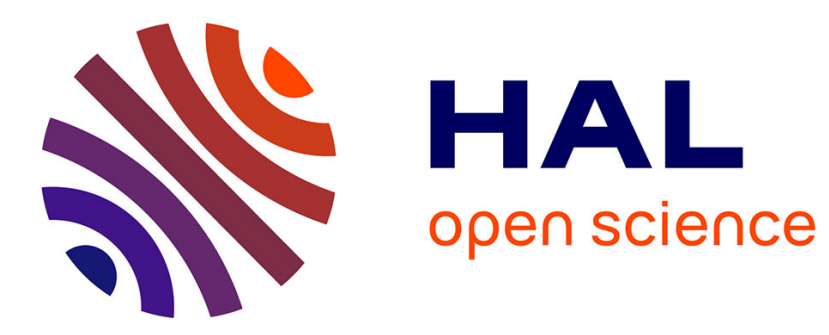

\title{
Sensorless direct torque control for salient-pole PMSM based on extended Kalman filter fed by AC/DC/AC converter
}

Fateh Benchabane, Abdenacer Titaouine, Ouafae Bennis, Khaled Yahia, Djamel Taibi, Abderazak Guettaf

\section{To cite this version:}

Fateh Benchabane, Abdenacer Titaouine, Ouafae Bennis, Khaled Yahia, Djamel Taibi, et al.. Sensorless direct torque control for salient-pole PMSM based on extended Kalman filter fed by AC/DC/AC converter. Frontiers in Energy, 2012, 6 (3), pp.247-254. 10.1007/s11708-012-0190-1 . hal-00741804

\author{
HAL Id: hal-00741804 \\ https://hal.science/hal-00741804
}

Submitted on 24 Oct 2012

HAL is a multi-disciplinary open access archive for the deposit and dissemination of scientific research documents, whether they are published or not. The documents may come from teaching and research institutions in France or abroad, or from public or private research centers.
L'archive ouverte pluridisciplinaire HAL, est destinée au dépôt et à la diffusion de documents scientifiques de niveau recherche, publiés ou non, émanant des établissements d'enseignement et de recherche français ou étrangers, des laboratoires publics ou privés. 


\title{
Sensorless Direct Torque Control For Salient - Pole PMSM Based on Extended Kalman Filter Fed By AC/DC/AC Converter
}

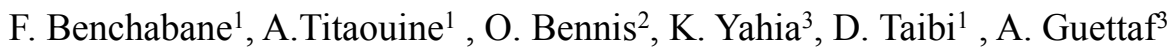 \\ ${ }^{1}$ MSE Laboratory, University of Biskra, B.P.145, 07000, Biskra, Algeria \\ ${ }^{2}$ PRISME Institute, University of Orléans, 21 rue Loigny La Bataille, 28000 Chartres, France \\ ${ }^{3}$ GEB Laboratory, University of Biskra, B.P.145, 07000, Biskra, Algeria
}

\begin{abstract}
In this paper, a new sensorless Interior Permanent Magnet Synchronous Motor (IPMSM) drives method with Extended Kalman Filter (EKF) for speed, rotor position and load torque estimation is proposed. The Direct Torque Control (DTC) technique for PMSM is receiving increasing attention due to the important advantages of the low dependence on motor parameters when compared with other motor control techniques. The Kalman filter is an observer for linear and non-linear systems and is based on the stochastic intromission, in others words, noise. The PMSM is fed by an indirect power electronic converter which is controlled by a sliding mode technique. The simulation tests that were performed for different operating conditions have confirmed the robustness of the overall system; and it is shown that the sliding mode technique has successfully minimized the different harmonics introduced by the line converter.
\end{abstract}

Key words - DTC; sensorless control; extended Kalman filter; Permanent Magnet Synchronous Motor; boost-rectifier.

\section{INTRODUCTION}

Permanent magnet synchronous motors (PMSMS) are widely used in many applications as high-performance variable-speed drives. Especially, an interior permanent magnet synchronous motor (IPMSM) can offer a highefficiency drive by utilizing the reluctance torque and a constant-power operation by the flux-weakening technique.

In order to control a stator current vector suitably and then achieve a high-performance drive, the information of rotor position and speed are necessary. In most variable-speed drives, some type of shaft sensor such as an optical encoder or resolver is connected to the rotor shaft. However, such sensor presents several disadvantages such as drive cost, machine size, reliability and noise immunity. Therefore, the sensorless control of PMSM is desired and various sensorless control strategies have been investigated [1][2][3]. The idea of combining the advantages of DTC and PMSM into a highly dynamic drive appeared in the literature in the late 1990's. In the past decade several authors have proposed ways to adapt DTC to work with PMSM [4].

Moreover DTC uses no current controller and no motor parameters other than the stator resistance, which yields a faster torque response and lower parameter dependence than with field oriented control [4].

Recently, motor drive systems without electromechanical sensors, so called 'sensorless drives', have gained increasing popularity in industrial applications because of inherent drawbacks of electromechanical sensors. In general, electromechanical sensors are used to obtain speed or position information of motors. A drawback of these sensors is performance degradation due to vibration or humidity [4][5].
The Kalman filter is an observer which provides optimal filtering with continuous Gaussian noises in the state and the measurement and known covariances of these noises [6] [7]. If the rotor speed and position (as extended states) are included in the dynamic model of PMSM, the extended Kalman filter EKF can be used to relinearize the non-linear state model for each new state estimate as it becomes available. Consequently, the EKF is considered to be the best solution to estimate the speed and position. A three-phase converter is used in this work. The power converter can only flow from $\mathrm{AC}$ to $\mathrm{DC}$, and the line current is not continuous. Because this type of AC-DC conversion does not control line current harmonics, the displacement power factor is poor and the DC side voltage is not constant [7][8]. One remedy is a reversible converter to replace the diode-bridge rectifier and to allow a reversible power line flow which allows the energy recovered from motor-load inertia to be fed back to the utility supply [8][9]. The DC-link voltage can be regulated by the sliding mode controller.

\section{PMSM MODEL}

The electrical and mechanical equations of the PMSM in the rotor reference $(\mathrm{d}-\mathrm{q})$ frame are as follows [10][11][12]:

$$
\left[\begin{array}{c}
\mathrm{V}_{\mathrm{d}} \\
\mathrm{V}_{\mathrm{q}}
\end{array}\right]=\left[\begin{array}{cc}
\mathrm{R}_{\mathrm{s}} & -\mathrm{L}_{\mathrm{q}}(\omega) \\
\mathrm{L}_{\mathrm{d}}() & \mathrm{R}_{\mathrm{s}}
\end{array}\right]\left[\begin{array}{c}
\mathrm{I}_{\mathrm{d}} \\
\mathrm{I}_{\mathrm{q}}
\end{array}\right]+\left[\begin{array}{cc}
\mathrm{L}_{\mathrm{d}} & 0 \\
0 & \mathrm{~L}_{\mathrm{q}}
\end{array}\right] \frac{\mathrm{d}}{\mathrm{dt}}\left[\begin{array}{c}
\mathrm{I}_{\mathrm{d}} \\
\mathrm{I}_{\mathrm{q}}
\end{array}\right]+\omega . \phi_{\mathrm{f}}\left[\begin{array}{l}
0 \\
1
\end{array}\right]
$$

The electromagnetic torque $\mathrm{T}_{\mathrm{e}}$ is given by:

$$
\mathrm{T}_{\mathrm{e}}=\mathrm{p}\left(\left(\mathrm{L}_{\mathrm{d}}-\mathrm{L}_{\mathrm{q}}\right) \mathrm{I}_{\mathrm{d}} \cdot \mathrm{I}_{\mathrm{q}}+\Phi_{\mathrm{f}} \cdot \mathrm{I}_{\mathrm{q}}\right)
$$

And the equation for the motor dynamic, on the other hand is

$$
\mathrm{T}_{\mathrm{e}}-\mathrm{T}_{1}=\mathrm{J} \frac{\mathrm{d} \Omega}{\mathrm{dt}}
$$

Figure. 1, presents the model of PMSM in d-q axis. 


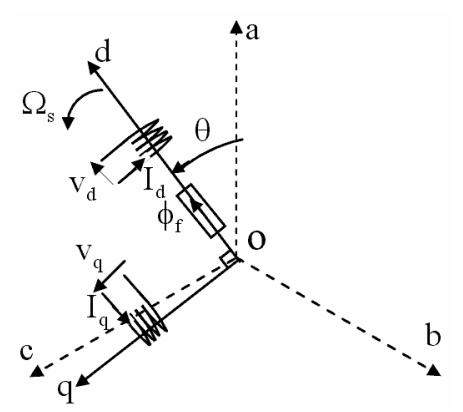

Figure.1. model of PMSM in d-q axis.

\section{III. MODELING AND CONTROL OF THE BOOST RECTIFIER}

The proposed system configuration is shown in figure 2 .

\section{A. a. Modeling Of The Boost Rectifier}

This circuit will be analyzed under the following assumptions [13, 14]:

1. The input $\mathrm{AC}$ voltage is a balanced three-phases supply;

2. The power switches are ideal;

3. All circuit elements are linear and time invariant.

The source voltages are assumed to be balanced and they are given by:

$$
\begin{aligned}
& \mathrm{v}_{1}=\mathrm{V}_{\mathrm{m}} \cos (\omega \mathrm{t}) \\
& \mathrm{v}_{2}=\mathrm{V}_{\mathrm{m}} \cos (\omega \mathrm{t}-2 \pi / 3) \\
& \mathrm{v}_{3}=\mathrm{V}_{\mathrm{m}} \cos (\omega \mathrm{t}+2 \pi / 3)
\end{aligned}
$$

where $\mathrm{Vm}$ and $\omega$ are respectively the amplitude of the phase voltage and angular frequency of the power source.

Referring to figure 1: By using Kirchhoff's voltage law on the AC side it yields:

$$
\mathrm{L} \frac{\mathrm{d}}{\mathrm{dt}} \mathrm{i}_{\mathrm{k}}+\mathrm{Ri}_{\mathrm{k}}=\mathrm{v}_{\mathrm{k}-}\left(\mathrm{v}_{\mathrm{k} 0}+\mathrm{v}_{0 \mathrm{n}}\right) \mathrm{k}=1,2,3
$$

where $\mathrm{k}$ indicates the phase.

The switching functions defined for the each converter are given by:

$$
\mathrm{S}_{\mathrm{k}}
$$

$$
\begin{array}{ll}
S_{k}=1 & \text { if } T_{k s} \text { is on and } T_{k i} \text { is off } \\
S_{k}=0 & \text { if } T_{k s} \text { is off and } T_{k i} \text { is on }
\end{array}
$$

Considering the switching functions, we have:

$$
\begin{gathered}
\mathrm{v}_{\mathrm{k} 0}=\mathrm{v}_{\mathrm{c}} \text { if } \mathrm{S}_{\mathrm{k}}=1 \\
\mathrm{v}_{\mathrm{k} 0}=0 \text { if } \mathrm{S}_{\mathrm{k}}=0 \\
\mathrm{v}_{0 \mathrm{~N}}=-\frac{\mathrm{v}_{\mathrm{c}}}{3} \sum_{\mathrm{k}=1}^{3} \mathrm{~S}_{\mathrm{k}}, \mathrm{k}=1,2,3
\end{gathered}
$$

Using the Kirchhoff's current law on the DC side and because of the relations described in (7) we have:

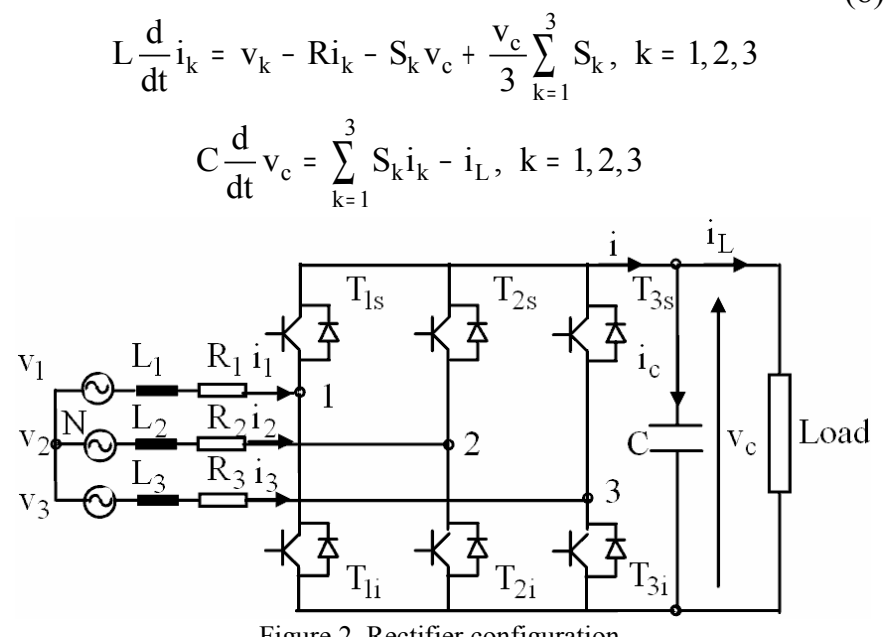

The following state-space model of the rectifier, in the three phases reference frame, can be obtained by:

$$
\frac{\mathrm{d}}{\mathrm{dt}}\left[\begin{array}{c}
\mathrm{i}_{1} \\
\mathrm{i}_{2} \\
\mathrm{i}_{3} \\
\mathrm{v}_{\mathrm{c}}
\end{array}\right]=\left[\begin{array}{ccccc}
-\frac{\mathrm{R}}{\mathrm{L}} & 0 & 0 & 0 & 0 \\
0 & -\frac{\mathrm{R}}{\mathrm{L}} & 0 & 0 & 0 \\
0 & 0 & -\frac{\mathrm{R}}{\mathrm{L}} & 0 & 0 \\
0 & 0 & 0 & 0 & 0
\end{array}\right]\left[\begin{array}{l}
\mathrm{i}_{1} \\
\mathrm{i}_{2} \\
\mathrm{i}_{3} \\
\mathrm{v}_{\mathrm{c}}
\end{array}\right]+
$$$$
\left[\begin{array}{ccc}
\frac{-2 \mathrm{v}_{\mathrm{c}}}{3 \mathrm{~L}} & \frac{\mathrm{v}_{\mathrm{c}}}{3 \mathrm{~L}} & \frac{\mathrm{v}_{\mathrm{c}}}{3 \mathrm{~L}} \\
\frac{\mathrm{v}_{\mathrm{c}}}{3 \mathrm{~L}} & \frac{-2 \mathrm{v}_{\mathrm{c}}}{3 \mathrm{~L}} & \frac{\mathrm{v}_{\mathrm{c}}}{3 \mathrm{~L}} \\
\frac{2 \mathrm{v}_{\mathrm{c}}}{3 \mathrm{~L}} & \frac{\mathrm{v}_{\mathrm{c}}}{3 \mathrm{~L}} & \frac{-2 \mathrm{v}_{\mathrm{c}}}{3 \mathrm{~L}} \\
\frac{\mathrm{i}_{1}}{\mathrm{C}} & \frac{\mathrm{i}_{2}}{\mathrm{C}} & \frac{\mathrm{i}_{3}}{\mathrm{C}}
\end{array}\right]\left[\begin{array}{l}
\mathrm{S}_{1} \\
\mathrm{~S}_{2} \\
\mathrm{~S}_{3}
\end{array}\right]+\left[\begin{array}{cccc}
\frac{1}{\mathrm{~L}} & 0 & 0 & 0 \\
0 & \frac{1}{\mathrm{~L}} & 0 & 0 \\
0 & 0 & \frac{1}{\mathrm{~L}} & 0 \\
0 & 0 & 0 & -\frac{1}{\mathrm{C}}
\end{array}\right]\left[\begin{array}{l}
\mathrm{v}_{1} \\
\mathrm{v}_{2} \\
\mathrm{v}_{3} \\
\mathrm{i}_{\mathrm{L}}
\end{array}\right]
$$

According to the system of equations (8) we can say that the main problem in the design of a control law of the boost rectifier is the occurrence of the control input function in both $\mathrm{AC}$ current and DC voltage

$$
\left(\mathrm{i}_{\mathrm{k}}\right) \quad\left(\mathrm{v}_{\mathrm{c}}\right)
$$

control systems of the

converter. Both input functions depend on the same duty ratio $\mathrm{S}_{\mathrm{k}}$

, by different dynamic behavior of $\mathrm{AC}$ input and $\mathrm{DC}$ output

of the boost rectifier. Input main voltages and currents should be sinusoidal without phase delay between voltage and current, and output DC voltage should have a constant value depending on input voltage and the parameters of the converter $[13,15]$.

\section{B. b. Sliding mode control of the Rectifier}

The block diagram of regulation is given by figure 3 .

According to figure 3 , the DC bus voltage error

$$
\left(\mathrm{v}_{\text {cref }}-\mathrm{v}_{\mathrm{c}}\right)
$$

used to synthesize a line current reference $\mathrm{I}_{\text {ref }}$ from a sliding mode controller (SMC). The currents references $i_{1 \text { ref }}, i_{2 \text { ref }}$ are 
generated from a sinusoidal model obtained through multiplying the current reference ${ }_{\mathrm{I}_{\text {ref }}}$ by the input voltage, in

order to ensure operation with a power factor "unit" [13,16], and input currents are measured. Values of currents, instantaneous and of reference are compared, and error signals are generated in order to produce switch impulses.

To control of the output DC voltage of the rectifier, one uses a SMC $[13,16]$ and through the sliding surface, one obtains the current ${ }_{\mathrm{I}_{\text {ref }}}$. The current ${ }_{\mathrm{I}_{\text {ref }}}$ is given by:

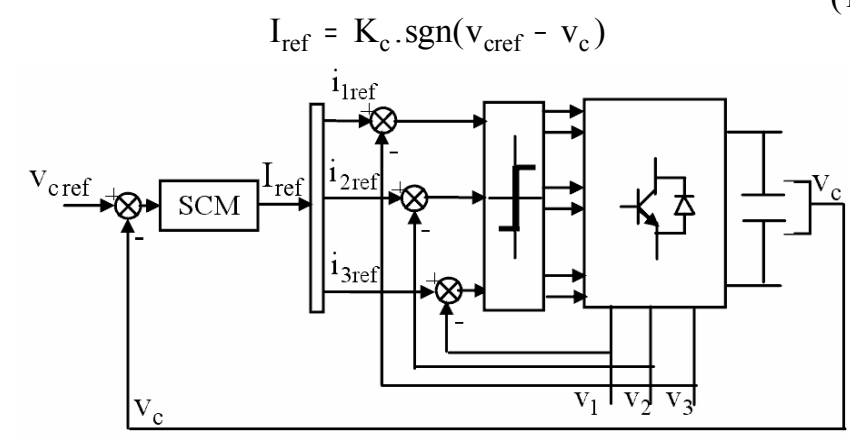

Figure.3. DC voltage control model with sliding mode controller.

\section{DIRECT TORQUE CONTROL SYSTEM}

Since M. Depenbrock and I. Takahashi proposed Direct Torque Control (DTC) for induction machines in the middle of 1980's, more than one decade has passed. It is getting more and more popular nowadays. The basic idea of DTC for induction motor is to control the torque and flux linkage by selecting the voltage space vectors properly, which is based on the relationship between the slip frequency and torque [4][17].

Estimation of the torque and the flux linkage, the basic principle of the DTC (Figure 4) is to select proper voltage vectors using a pre-defined switching table. The selection is based on the hysteresis control of the stator flux linkage and the torque. In the basic form the stator flux linkage is estimated with: [4] [18]

$$
\phi_{\mathrm{s}}(\mathrm{t})=\int_{0}^{\mathrm{t}}\left(\mathrm{V}_{\mathrm{s}}-\mathrm{R}_{\mathrm{s}} \mathrm{I}_{\mathrm{s}}\right) \mathrm{dt}+\phi_{\mathrm{s} 0}
$$

Let us replace the estimate of the stator voltage with the true value and write it as:

$$
\mathrm{V}_{\mathrm{s}}\left(\mathrm{S}_{\mathrm{A}} \mathrm{S}_{\mathrm{B}} ; \mathrm{S}_{\mathrm{C}}\right)=\frac{2}{3} \mathrm{U}_{0}\left(\mathrm{~S}_{\mathrm{A}}+\mathrm{S}_{\mathrm{B}} \mathrm{e}^{\mathrm{j} 2 \pi / 3}+\mathrm{S}_{\mathrm{C}} \mathrm{e}^{\mathrm{j} 4 \pi / 3}\right)
$$

$\mathrm{Sa}, \mathrm{Sb}$ and $\mathrm{Sc}$ represent the states of the three phase legs 0 meaning that the phase is connected to the negative and 1 meaning that the phase is connected to the positive leg.

The stator current space vector is calculated from measured currents $i_{a}, i_{b}, i_{c}$ :

$$
\mathrm{i}_{\mathrm{s}}=\frac{2}{3}\left(\mathrm{i}_{\mathrm{a}}+\mathrm{i}_{\mathrm{b}} \mathrm{e}^{\mathrm{j} 2 \pi / 3}+\mathrm{i}_{\mathrm{c}} \mathrm{e}^{\mathrm{j} 4 \pi / 3}\right)
$$

The voltage vectors obtained this way are shown in Figure 5.

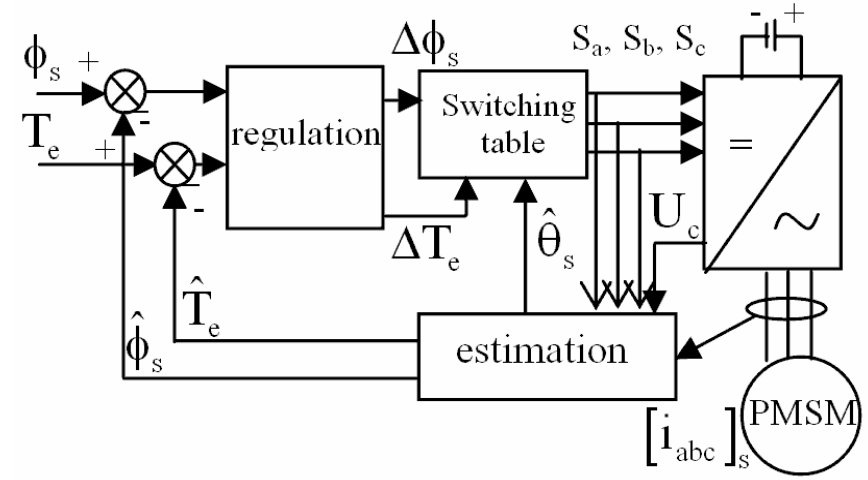

Figure.4. System diagram of a typical DTC PMSM drive system.

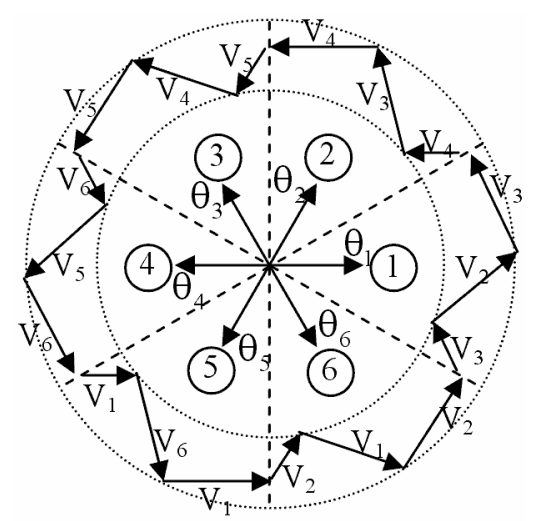

Figure.5.Voltage vectors for DTC.

The composite $\alpha$ and $\beta$ of vector can be obtained: $\phi_{\mathrm{s}}$

$$
\left\{\begin{array}{l}
\phi_{\mathrm{s} \alpha}=\int_{0}^{\mathrm{t}}\left(\mathrm{V}_{\mathrm{s} \alpha}-\mathrm{R}_{\mathrm{s}} \mathrm{I}_{\mathrm{s} \alpha}\right) \mathrm{dt} \\
\phi_{\mathrm{s} \beta}=\int_{0}^{\mathrm{t}}\left(\mathrm{V}_{\mathrm{s} \beta}-\mathrm{R}_{\mathrm{s}} \mathrm{I}_{\mathrm{s} \beta}\right) \mathrm{dt}
\end{array}\right.
$$

Stator flux linkage written:

$$
\phi_{\mathrm{s}}=\sqrt{\left(\phi_{\mathrm{s} \alpha}\right)^{2}+\left(\phi_{\mathrm{s} \beta}\right)^{2}}
$$

The angle $\theta_{\mathrm{s}}$ is equal to:

$$
\theta_{\mathrm{s}}=\operatorname{arctg} \frac{\phi_{\$ \beta}}{\phi_{\mathrm{su}}}
$$

The torque can then be estimated with:

$$
T_{e}=\phi_{s \alpha} I_{s \beta}-\phi_{s \beta} I_{s \alpha}
$$

The voltage vector plane is divided into six sectors so that each voltage vector divides each region into two equal parts.

In each sector, four of the six non-zero voltage vectors may be used. Also zero sectors are allowed. All the possibilities can be tabulated into a switching table (Table I). The output of the torque hysteresis comparator is denoted as $\tau$, the output of the flux hysteresis comparator as $\Phi$ and the flux linkage sector is denoted as $\theta$. 


\section{DESIGN OF EKF OBSERVER}

Accurate and robust estimation of motor variables which are not measured is crucial for high performance sensorless drives. A multitude of observers have been proposed, but only a few are able to sustain persistent and accurate wide speed range sensorless operation. At very low speed, theirs performances are poor. One of the reasons is the high sensitivity of the observers to unmodeled nonlinearities, disturbance and model parameters detuning.

The Kalman filter provides a solution that directly cares for the effects of disturbance noises including system and measurement noises. The errors in parameters will also normally be handled as noise [19][20].

The dynamic state model for non non-linear stochastic machine is as follows where all symbols in the formulations denote matrices or vectors [21, 22]:

$$
\left\{\begin{array}{l}
\dot{x}(t)=f(x(t), u(t), t)+w(t) \\
y(t)=h(x(t), t)+v(t)
\end{array}\right.
$$

$\mathrm{w}(\mathrm{t})$

: System noise vector.

$\mathrm{v}(\mathrm{t})$

: Measurement noise vector

$\mathrm{w}, \mathrm{v}$ : are unrelated and zero mean stochastic processes.

\begin{tabular}{|c|c|c|c|c|c|c|c|}
\hline $\mathrm{K}_{\phi}$ & $\mathrm{K}_{\mathrm{c}}$ & $S_{1}$ & $S_{2}$ & $S_{3}$ & $S_{4}$ & $\mathrm{~S}_{5}$ & $\mathrm{~S}_{6}$ \\
\hline \multirow{3}{*}{1} & $V_{1}$ & $\mathrm{~V}_{6}$ & $V_{5}$ & $V_{4}$ & $V_{2}$ & $V_{2}$ & 1 \\
\hline & $\mathrm{V}_{0}$ & $V_{7}$ & $\mathrm{~V}_{0}$ & $V_{7}$ & $\mathrm{~V}_{0}$ & $V_{7}$ & 0 \\
\hline & $V_{5}$ & $V_{4}$ & $V_{3}$ & $V_{2}$ & $V_{1}$ & $V_{6}$ & 1- \\
\hline \multirow{3}{*}{ 0 } & $V_{2}$ & $\mathrm{~V}_{1}$ & $V_{6}$ & $V_{5}$ & $V_{4}$ & $V_{3}$ & 1 \\
\hline & $V_{7}$ & $\mathrm{~V}_{0}$ & $V_{7}$ & $\mathrm{~V}_{0}$ & $V_{7}$ & $V_{0}$ & 0 \\
\hline & $V_{4}$ & $V_{3}$ & $V_{2}$ & $V_{1}$ & $V_{6}$ & $V_{5}$ & 1- \\
\hline
\end{tabular}

A recursive algorithm is presented for the discrete time case. For the given sampling time $\mathrm{T}_{\mathrm{s}}$, both the optimal estimate sequence $\underset{\mathrm{x}_{\mathrm{k} / \mathrm{k}}}{\text { and its covariance matrix }} \mathrm{P}_{\mathrm{k} / \mathrm{k}}$ generated by the filter go through a two step loop.

The first step (prediction) performs a prediction of both quantities based on the previous estimates

$$
\mathrm{x}_{\mathrm{k}-1 / \mathrm{k}-1}
$$

and the

mean voltage vector actually applied to the system in the period from $\mathrm{T}_{\mathrm{k}-1}$ to $T_{k} . \mathrm{F}$ is the system gradient matrix (Jacobean matrix).

$$
\begin{gathered}
F(\tilde{x}(t), t)=\left.\frac{\partial f(x(t), u(t), t)}{\partial x^{T}(t)}\right|_{x(t)=\tilde{x}(t)} \\
x_{k / k-1}=x_{k-1 / k-1}+T_{s} \cdot f\left(x_{k-1 / k-1}, u_{k-1}\right)
\end{gathered}
$$

$$
\mathrm{P}_{\mathrm{k} / \mathrm{k}-1}=\mathrm{P}_{\mathrm{k} / \mathrm{k}-1}+\left(\mathrm{FP}_{\mathrm{k}-1 / \mathrm{k}-1}+\mathrm{P}_{\mathrm{k}-1 / \mathrm{k}-1} \mathrm{~F}^{\mathrm{T}}\right) \cdot \mathrm{T}_{\mathrm{s}}+\mathrm{Q}
$$

The second step (innovation) corrects the predicted state estimate and its covariance matrix trough a feedback correction scheme that makes use of the actual measured quantities; this is realized by the following recursive relations:

$$
\begin{gathered}
\mathrm{x}_{\mathrm{k} / \mathrm{k}}=\mathrm{x}_{\mathrm{k} / \mathrm{k}-1}+\mathrm{K}_{\mathrm{k}}\left(\mathrm{Y}_{\mathrm{k}}-\mathrm{Hx}_{\mathrm{k} / \mathrm{k}-1}\right) \\
\mathrm{P}_{\mathrm{k} / \mathrm{k}}=\mathrm{P}_{\mathrm{k} / \mathrm{k}-1}-\mathrm{K}_{\mathrm{k}} \mathrm{HP}_{\mathrm{k} / \mathrm{k}-1}
\end{gathered}
$$

Where the filter gain matrix is defined by:

$$
\mathrm{k}_{\mathrm{k}}=\mathrm{P}_{\mathrm{k} / \mathrm{k}-1} \mathrm{H}^{\mathrm{T}}\left(\mathrm{HP}_{\mathrm{k} / \mathrm{k}-1} \mathrm{H}^{\mathrm{T}}+\mathrm{R}\right)^{-1}
$$

$\mathrm{H}$ is transformation matrix.

$$
H(\tilde{x}(t), t)=\left.\frac{\partial h}{\partial x}\right|_{x(t)=\tilde{x}(t)}
$$

The proposed EKF observer is designed in rotor reference frame ( frame) given by figure 6 .

$$
\mathrm{d}, \mathrm{q}
$$

The state vector is chosen to be:

Input:

$$
\mathrm{X}=\left[\begin{array}{lllll}
\mathrm{I}_{\mathrm{d}} & \mathrm{I}_{\mathrm{q}} & \Omega & \theta & \mathrm{T}_{1}
\end{array}\right]^{\mathrm{T}}
$$

Output:

$$
\mathrm{U}=\left[\begin{array}{ll}
\mathrm{V}_{\mathrm{d}} & \mathrm{V}_{\mathrm{q}}
\end{array}\right]^{\mathrm{T}}
$$

$\mathrm{Y}=\left[\begin{array}{ll}\mathrm{I}_{\mathrm{d}} & \mathrm{I}_{\mathrm{q}}\end{array}\right]$

$\mathrm{I}_{\mathrm{d}}, \mathrm{I}_{\mathrm{q}}{ }^{\text {and }} \mathrm{V}_{\mathrm{d}}, \mathrm{V}_{\mathrm{q}}$ are motor stator currents, voltages in rotor reference frame.

The critical step in the EKF is the search for the best covariance matrices $\mathrm{Q}$ and $\mathrm{R}$ have to be set-up based on the stochastic properties of the corresponding noise. The noise covariance $\mathrm{R}$ accounts for the measurement noise introduced by the current sensors and quantization errors of the $\mathrm{A} / \mathrm{D}$ converters $[19,23]$. Increasing $\mathrm{R}$ indicates stronger disturbance of the current. The noise is weighted less by the filter, causing also a slower transient performance of system.

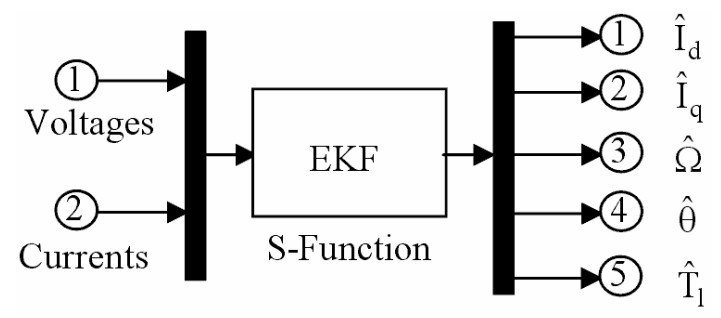

Figure. 6. S-Function representation of the EKF.

The noise covariance $\mathrm{Q}$ reflects the system model inaccuracy, the errors of the parameters and the noise introduced by the voltage estimation [19, 23]. $\mathrm{Q}$ has to be increased at stronger noise driving the system, entailing a more heavily weighting of the measured current and a faster transient performance. 
An initial matrix $\mathrm{P}_{0}$ represents the matrix of the covariance in knowledge of the initial condition. Varying ${ }_{\mathrm{P}_{0}}$ affects neither the transient performance nor the steady state condition of the system. In this study, the value of these elements is tuned "manually", by running several simulations. This is may be one of the major drawbacks of the Kalman filter.

The blocks DTC (Direct Torque Control), SMC (slidingmode control) are regulators, the first controller for speed, and the second is the sliding mode control regulator for rectifier.

Figure 7 shows the proposed Sensorless Direct torque control using EKF. In this study, the outputs of a PWM voltage source inverter are used as the control inputs for the EKF. These signals contain components at high frequencies, which are used as the required noise by the Kalman filter. Thus, no additional external signals are then needed.

$$
\begin{aligned}
& \mathrm{f}(\mathrm{x}(\mathrm{k}), \mathrm{u}(\mathrm{k}))=\left[\begin{array}{lllll}
\mathrm{I}_{\mathrm{d}} & \mathrm{I}_{\mathrm{q}} & \Omega & \theta & \mathrm{T}_{1}
\end{array}\right]^{\mathrm{T}}= \\
& {\left[\begin{array}{l}
\left(1-\mathrm{T}_{\mathrm{s}} \frac{\mathrm{R}_{\mathrm{s}}}{\mathrm{L}_{\mathrm{d}}}\right) \mathrm{I}_{\mathrm{d}}+\mathrm{p} \Omega \mathrm{T}_{\mathrm{s}} \frac{\mathrm{L}_{\mathrm{q}}}{\mathrm{L}_{\mathrm{d}}} \mathrm{I}_{\mathrm{q}}+\mathrm{T}_{\mathrm{s}} \frac{1}{\mathrm{~L}_{\mathrm{d}}} \mathrm{V}_{\mathrm{d}} \\
\left(-\mathrm{p} \Omega \mathrm{T}_{\mathrm{s}} \frac{\mathrm{L}_{\mathrm{d}}}{\mathrm{L}_{\mathrm{q}}}\right) \mathrm{I}_{\mathrm{d}}+\left(1-\mathrm{T}_{\mathrm{s}} \frac{\mathrm{R}_{\mathrm{s}}}{\mathrm{L}_{\mathrm{q}}}\right) \mathrm{I}_{\mathrm{q}}-\mathrm{T}_{\mathrm{s}} \frac{\phi_{\mathrm{sf}}}{\mathrm{L}_{\mathrm{q}}} \mathrm{p} \Omega+\mathrm{T}_{\mathrm{s}} \frac{1}{\mathrm{~L}_{\mathrm{q}}} \mathrm{V}_{\mathrm{q}} \\
\mathrm{pT}_{\mathrm{s}} \frac{\mathrm{L}_{\mathrm{d}}-\mathrm{L}_{\mathrm{q}}}{\mathrm{J}} \mathrm{I}_{\mathrm{q}} \mathrm{I}_{\mathrm{d}}+\mathrm{pT}_{\mathrm{s}} \frac{{ }_{\mathrm{sf}}}{\mathrm{J}} \mathrm{I}_{\mathrm{q}}+\left(1-\mathrm{T}_{\mathrm{s}} \frac{\mathrm{f}}{\mathrm{J}}\right) \Omega-\mathrm{T}_{\mathrm{s}} \frac{1}{\mathrm{~J}} \mathrm{~T}_{1} \\
\Omega \\
1
\end{array}\right.}
\end{aligned}
$$

where:

$$
h=\left[\begin{array}{ll}
I_{d} & I_{q}
\end{array}\right]^{T}
$$

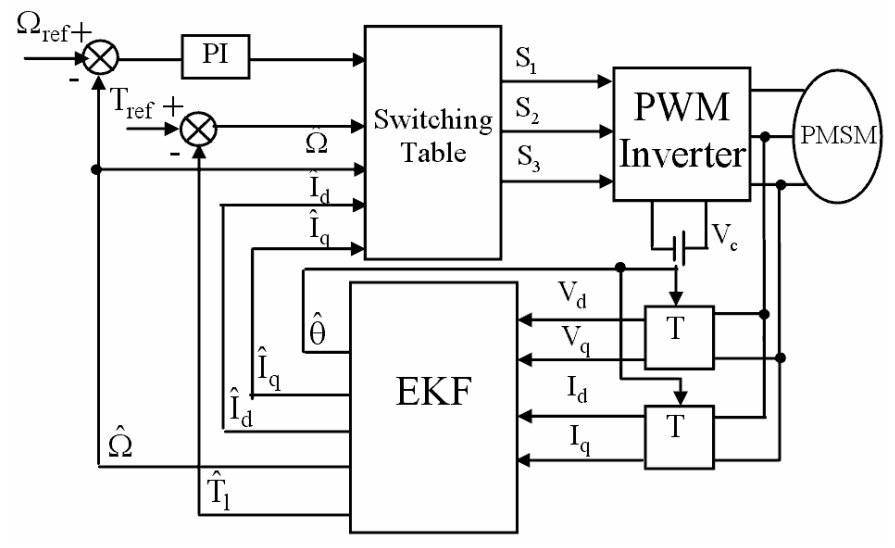

Figure.7. System of a typical DTC PMSM drive with an EKF .

\section{Simulation Results}

\section{A. a. Simulation Results of SMC Rectifier}

The simulation conditions are given in the appendix.
In order to demonstrate the feasibility of the proposed control method, the system shown in Figure 1 has been simulated. Figure 8 shows that the output voltage of the rectifier is well controlled to $540 \mathrm{v}$. Therefore, the output DC voltage response is completely robust with the unity power factor at the AC side of the boost rectifier.

Simulation results obtained were in good performance as it is expected. The strategy control was very robust to uncertain parameters and gave a very high power factor and small ripple in the current line supply.

\section{B. $\quad$ b. Simulation results of sensorless direct torque control for PMSM}

Extensive simulations have been performed using Matlab/ Simulink Software to examine control algorithm of the DTC applied for PMSM presented in Figure 7.

When there are some initial position errors $(\pi / 3)$, the rotor speed and position estimation errors are shown in figure 9 and figure 10. It can be seen that the initial position error causes some errors in the speed and position estimation at the beginning, but the extended Kalman filter can track the real values very quickly.

When the motor starts up at $0 \mathrm{~s}$, and there is some load torque impact at $1 \mathrm{~s}$, the observed and real load torque is shown in figure 11. It can be seen that the observed load torque can track the real torque very well. These responses illustrate high performance of the proposed EKF observer during transients and steady state.

In order to check the usability, electromagnetic torque is change at $0.2 \mathrm{~s}$ as step signal when sensorless drive is being performed.

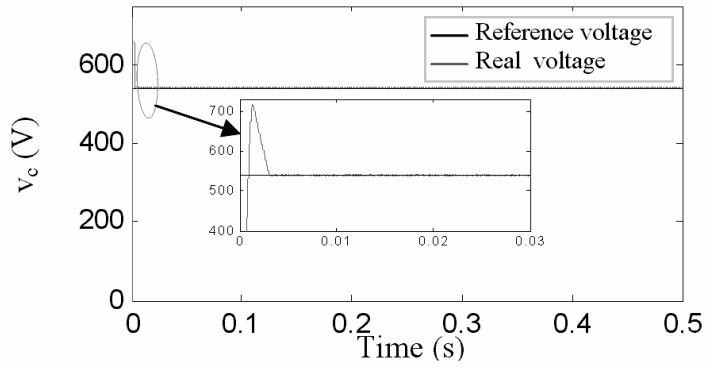

Figure. 8. Simulation results of the rectifier Output voltage.

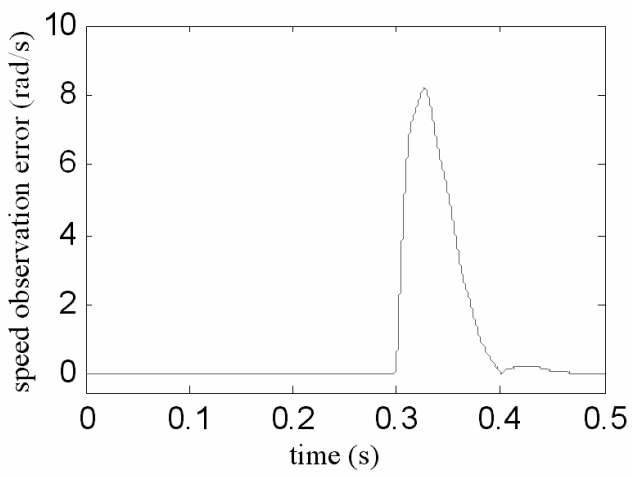

Figure. 9. Speed observation errors. 


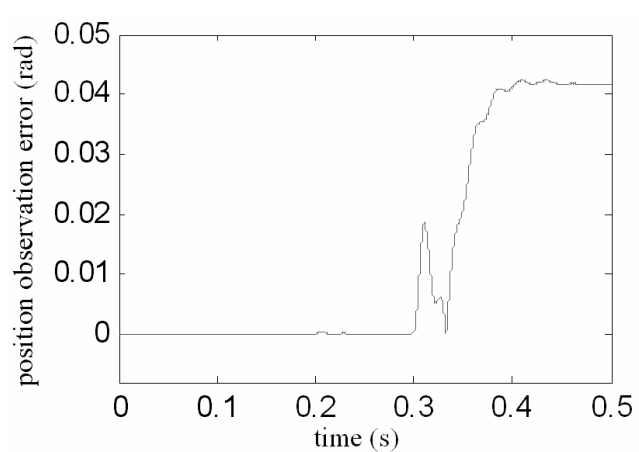

Figure. 10. Position observation errors.

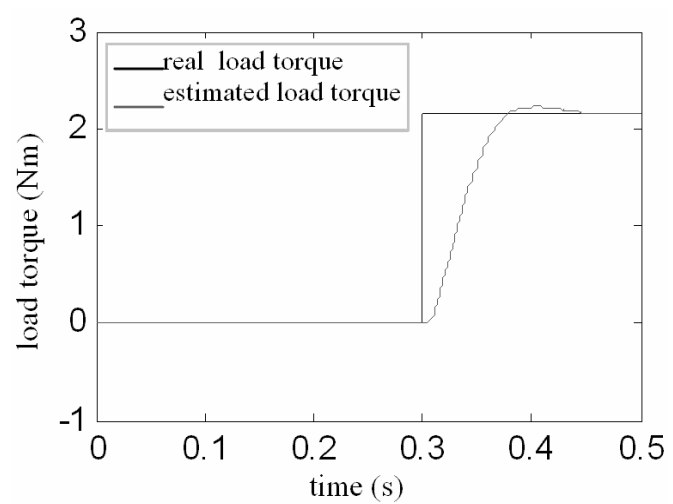

Figure. 11. Observed and real load torque.

Figure 12 shows the result. From Figure12, The torque follows perfectly the value of record with negligible effect on the speed that is rapidly restored to its reference.

Figure 13, presents the estimated flux, we also note that the flow is not affected by the variation of the load. The flux reaches its reference control with no overshoot.

The estimation algorithm is robust because the variation of the elctromagnic is important and the estimated elctromagnic follows the real speed when the motor starts and at the moment of elctromagnic inversion.

Figure 14. Presents trajectory of the estimated stator flux components, the stator flux trajectory is almost circular. Figure 15. Shows the evolution of flux Alpha, flux Betha.

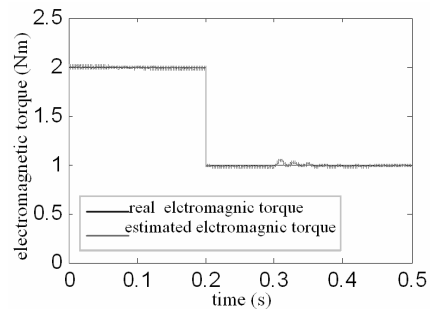

Figure.12. elctromagnic torque.

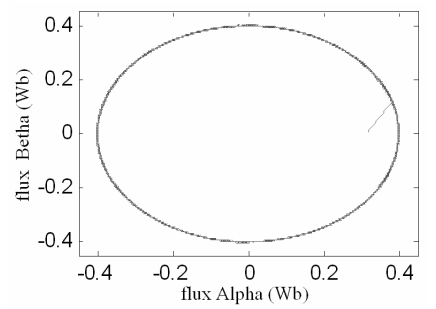

Figure. 14. Trajectory of the estimated stator flux components.

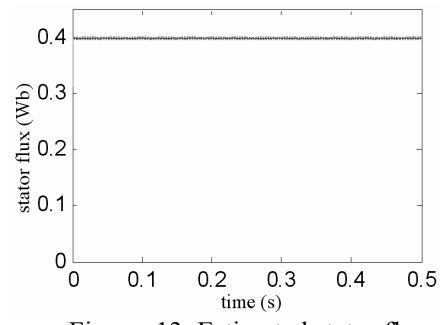

Figure. 13. Estimated stator flux.

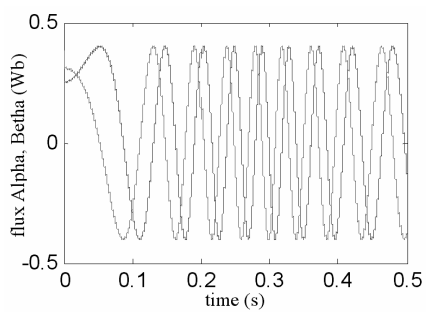

Figure. 15. Evolution of flux $\alpha, \beta$.

\section{CONCLUSION}

In this paper, the EKF approach is proposed to estimate the exact rotor speed, position and load torque for PMSM sensorless direct torque control (DTC). The observed load torque was used as the feed-forward compensation of the reference torque.

For the rectifier, the obtained simulation results show the efficiency and the precision of the sliding mode control.

For the EKF, the simulation results of the speed, position and load torque estimation are very satisfactory of view point estimation error, strength and stability of global training system in any operating condition.

\section{Appendix}

Parameters of the system used in simulation:

Parameters of the PMSM:

Rated power $1500 \mathrm{w}$

Rated speed $3000 \mathrm{rpm}$

Stator winding resistance $1.5 \Omega$

Stator winding direct, quadrate inductance $0.0424 \mathrm{H}$, $0.0795 \mathrm{H}$.

Rotor flux $0.314 \mathrm{~Wb}$

Viscous friction $0.00008 \mathrm{Nm} / \mathrm{rad} / \mathrm{s}$

Inertia $0.003 \mathrm{~kg} \mathrm{~m} 2$

Pairs pole number 4

Nominal current, voltage line $15 \mathrm{~A}, 220 \mathrm{~V}$.

Parameters of the PWM converter:

Supply's voltage and frequency: $220 \mathrm{~V}(\mathrm{rms}), 50 \mathrm{~Hz}$

Line's inductor and resistance $0.002 \mathrm{H}, 0.08 \Omega$

Output capacitors $0.0025 \mathrm{~F}$

PWM carrier frequency $1 \mathrm{kHz}$

\section{ReFERENCES}

[1] S. Morimoto, K. Kawamoto, M. Sanada, Sensorless Control Strategy for Salient-Pole PMSM Based on Extended EMF in Rotating Reference Frame, The International Conference on "Computer as a Tool", EUROCON, Warsaw, (2007) 1851-1855.

[2] J. P. Johnson, M. Ehsani, Y. Guzelgunler, Review of Sensorless Methods for Burushless DC, Proc. 1999. IEEE IAS Ann. Meet., (1999) 143-150.

[3] Z. Chen, M. Tomita, S. Ichikawa, Sensorless Control of Interior Permanent Magnet Synchronous Motor by Estimation of an Extended Electromotive Force, Proc. 2000 IEEE IAS Ann. Meet., (2000) 18141819.

[4] M. S. Merzoug, H. benalla, H. Naceri, Speed Estimation Using Extended Filter Kalman for the Direct Torque Controlled Permanent Magnet Synchronous Motor (PMSM), 2009 Second International Conference on Computer and Electrical Engineering, Warsaw, (2007) 1851-1855.

[5] T. J. Vyncke, R. K. Boel, J. A Melkebeek, Direct Torque Control of Permanent Magnet Synchronous Motors - An Overview, 3rd IEEE Benelux Young Researchers Symposium in Electrical Power Engineering, no. 28, Ghent, Belgium, (2006) p. 5.

[6] Z. Zheng, M. Fadel, Y. Li, High performance PMSM sensorless control with load torque observation, The International Conference on "Computer as a Tool", EUROCON, Warsaw, (2007) 1851-1855.

[7] F. Benchabnae, A. Titaouine, Sensorless Control Strategy For Permanent Magnet Synchronous Motor Fed By AC/DC/AC Converter, IEEE International Conference on Electrical Machines, Italy, (2010) 1-6.

[8] Y. S. Lu, X. W. Wang, Sliding-mode repetitive learning control with integral sliding-mode perturbation compensation, ISA Transactions, Vol. 48, Issue 2, (2009), 156-165. 
[9] Y. Y. He, W. Jiang, A new variable structure controller for direct torque controlled interior permanent magnet synchronous motor drive, Proceedings of the IEEE International Conference on Automation and Logistics, (2007) 2349-2354.

[10] M. Cernat, V. Comnac, M. Cotorogea, P. Korondi, S. Ryvkin, R.M. Cernat, Sliding mode control o4f interior permanent magnet synchronous motors, VII IEEE International Power Electronics Congress, Acapulco, MEXICO, (2000) 48-53.

[11] M. T. Benchouia, S.E. Zouzou, A. Golea, A. Ghamri, A.Modeling and simulation of variable speed system with adaptive fuzzy controller application to PMSM, IEEE International Conference on Industrial Technology ICIT, Vol. 2, (2004) 683-687.

[12] A. Titaouine, F. Benchabane, Application of Ac/Dc/Ac converter for sensorless nonlinear control of permanent magnet synchronous motor, IEEE Internatinal Conference on Systems, Man and Cybernetics, Turkey, (2010) 2282-2287.

[13] A. Hadri-Hamida, A. Allag, M.Y. Hammoudi, S.M. Mimoune, S. Zerouali, M.Y. Ayad, M. Becherif, E. Miliani, A. Miraoui, A nonlinear adaptive backstepping approach applied to a three phase PWM AC-DC converter feeding induction heating, Communications in Nonlinear Science and Numerical Simulation, Vol. 14, Issue 4, (2009) 1515-1525.

[14] F. Benchabane, A. Titaouine, Systematic fuzzy sliding mode approach combined with extended Kalman filter for permanent magnet synchronous motor control", IEEE Internatinal Conference on Systems, Man and Cybernetics, Turkey, (2010) 2169-2174.

[15] K. Jezemik, VSS control of unity power factor, IEEE Transactions on Industrial Electronics, Vol. 46, (1999) 325-332.
[16] G. D. Andreescu; A. Popa, A. Spilca, Two Sliding Mode Based Observers for Sensorless Control of PMSM Drives, Electric Power Components and Systems, Vol. 30, Issue 2, (2002) 121-133.

[17] L. Tang, L. Zhong, M. F. Rahman, Y. Hu, A Novel Direct Torque Control for Interior Permanent Magnet Synchronous Machine Drive System with Low Ripple in Torque and Flux-A Speed Sensorless Approach, Proceedings of the 37th IEEE IAS'02 Industry Applications Society Annual Meeting, Pittsburgh, U.S.A., Vol. 1, (2002) 104-111.

[18] M. F. Rahman, L. Zhong, E. Haque, M. A. Rahman, A Direct TorqueControlled Interior Permanent-Magnet Synchronous Motor Drive Without a Speed Sensor, IEEE Trans. Energy Conversion, Vol. 18, no. 1, (2003) 17-22.

[19] D. Janiszewski, Extended Kalman Filter based speed sensorless PMSM control with load reconstruction, The 23nd Annual Conference of the IEEE Industrial Electronics Society, (2006) 1465-1468.

[20] M.S. Sayed Ahmed, Z. Ping, Y.J. Wu, Modified sliding mode controller with extended Kalman filter for stochastic systems, IEEE International Conference on Control and Automation, Guangzhou, (2007) 630-635.

[21] A. Titaouine, a. Moussi, sensorless nonlinear control of permanent magnet synchronous motor using the extended kalman filtre, asian journal of information technology, Vol. 5, (2006)1416-1422.

[22] S. Sayeef, M.F. Rahman, Comparison of proportional + integral control and variable structure control of interior permanent magnet synchronous motor drives, 38th IEEE Power Electronics Specialists Conference, Orlando, USA, (2007) 1645-1650.

IX. [23] N. Senthil Kumar, V. Sadasivam, H. M. Asan Sukriya, A comparative study of pi, fuzzy, and ann controllers for chopper-fed dc drive with embedded systems approach, Electric Power Components and Systems, Vol. 36, Issue 7, (2008) 680-695. 